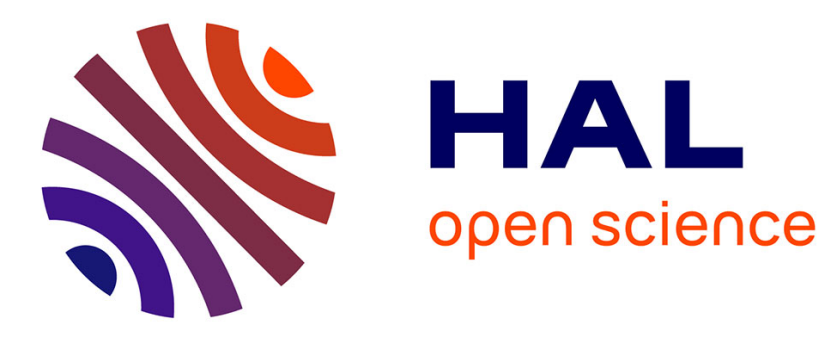

\title{
The role of bone intrinsic properties measured by infrared spectroscopy in whole lumbar vertebra mechanics: Organic rather than inorganic bone matrix?
}

Julien Wegrzyn, Jean-Paul Roux, Delphine Farlay, Hélène Follet, Roland Chapurlat

\section{To cite this version:}

Julien Wegrzyn, Jean-Paul Roux, Delphine Farlay, Hélène Follet, Roland Chapurlat. The role of bone intrinsic properties measured by infrared spectroscopy in whole lumbar vertebra mechanics: Organic rather than inorganic bone matrix?. BONE, 2013, 56 (2), pp.229-233. 10.1016/j.bone.2013.06.006 . hal-01183688

\section{HAL Id: hal-01183688 \\ https://hal.science/hal-01183688}

Submitted on 6 Nov 2019

HAL is a multi-disciplinary open access archive for the deposit and dissemination of scientific research documents, whether they are published or not. The documents may come from teaching and research institutions in France or abroad, or from public or private research centers.
L'archive ouverte pluridisciplinaire $\mathbf{H A L}$, est destinée au dépôt et à la diffusion de documents scientifiques de niveau recherche, publiés ou non, émanant des établissements d'enseignement et de recherche français ou étrangers, des laboratoires publics ou privés. 


\section{A R T I C L E I N F O}

\section{Article history:}

Received 4 February 2013

Revised 24 May 2013

Accepted 10 June 2013

Available online $\mathrm{xxxx}$

Edited by: David Burr

\section{Keywords:}

Bone mechanics

Vertebra

Bone matrix

Collagen maturity

Bone microarchitecture

\begin{abstract}
A B S T R A C T
Whole bone strength is determined by bone mass, microarchitecture and intrinsic properties of the bone matrix. 26 However, few studies have directly investigated the contribution of bone tissue material properties to whole bone 27 strength in humans. This study assessed the role of bone matrix composition on whole lumbar vertebra mechan- 28 ics. We obtained 17 fresh frozen human lumbar spines ( $8 \mathrm{~W}, 9 \mathrm{M}$, aged $76 \pm 11$ years). L3 bone mass was mea- 29 sured by DXA and microarchitecture by $\mu-C T$ with a $35 \mu \mathrm{m}$-isotropic resolution. Microarchitectural parameters 30 were directly measured: Tb.BV/TV, SMI, Tb.Th, DA, Ct.Th, Ct.Po and radius of anterior cortical curvature. Failure 31 load $(\mathrm{N})$, stiffness $(\mathrm{N} / \mathrm{mm})$ and work to failure $(\mathrm{N} . \mathrm{mm})$ were extracted from quasi-static uniaxial compressive 32 testing performed on L3 vertebral bodies. FTIRM analysis was performed on $2 \mu \mathrm{m}$-thick sections from L2 33 trabecular cores, with a Perkin-Elmer GXII Auto-image Microscope equipped with a wide band detector. 34 Twenty measurements per sample were performed at $30 * 100 \mu \mathrm{m}$ of spatial resolution. Each spectrum was col- 35 lected at $4 \mathrm{~cm}^{-1}$ resolution and 50 scans in transmission mode. Mineral and collagen maturity, and mineraliza- 36 tion and crystallinity index were measured. There was no association between the bone matrix characteristics 37 and bone mass or microarchitecture. Mineral maturity, mineralization and crystallinity index were not related 38 to whole vertebra mechanics. However, collagen maturity was positively correlated with whole vertebra failure 39 load and stiffness ( $\mathrm{r}=0.64, \mathrm{p}=0.005$ and $\mathrm{r}=0.54, \mathrm{p}=0.025$, respectively). The collagen maturity (3rd step) 40 in combination with bone mass (i.e. BMC, 1st step) and microarchitecture (i.e. Tb.Th, 2nd step) improved the 41 prediction of whole vertebra mechanical properties in forward stepwise multiple regression models, together 42 explaining $71 \%$ of the variability in whole vertebra stiffness $(p=0.001)$. In conclusion, we demonstrated a sub- 43 stantial contribution of collagen maturity, but not mineralization parameters, to whole bone strength of human 44 lumbar vertebrae that was independent of bone mass and microarchitecture.
\end{abstract}

\section{Introduction}

Mechanical principles dictate that whole bone strength is determined by bone mass, bone microarchitecture and intrinsic properties of the bone matrix [1,2]. Beside bone mass, the contribution of microarchitecture and its spatial distribution (i.e.; microarchitecture heterogeneity) has been extensively explored biomechanically and clinically. It is probably the best understood among the different levels of analysis [3-7]. Specifically, impairment in trabecular and cortical microarchitecture impacts dramatically on whole bone strength and the risk of fragility fracture, independently of areal bone mineral density (aBMD) [3,4]. In addition, the post-fracture mechanical behavior of vertebrae after initial mild fracture was demonstrated ex-vivo to be related to bone microarchitecture but

\footnotetext{
* Corresponding author at: Department of Orthopedic Surgery - Pavillon T, Hôpital Edouard Herriot, 5, Place d'Arsonval, 69437 Lyon, France. Fax: +33 472117637.

E-mail address: julien.wegrzyn@chu-lyon.fr (J. Wegrzyn).

1 These authors contributed equally to this work
}

not bone mass [5]. Abnormalities in age-related enzymatic and 63 non-enzymatic collagen cross-links affect the mineralization process, 64 and can lead to microdamage accumulation and impaired bone me- 65 chanical behavior therefore contributing to fracture risk prediction. 66 However, the direct contribution of bone matrix properties to bone 67 strength is more difficult to assess and therefore, remains poorly under- 68 stood at the whole bone level in humans [2,8-11]. Micro- or nano- 69 indentation techniques in human iliac bone samples demonstrated a 70 strong relationship between the bone matrix and local tissue mechanical 71 behavior [12,13]. Along with mineralized matrix, the organic matrix ac- 72 counts for one third of the variance in bone microhardness at the bone 73 structural unit level [12]. Particularly, collagen maturity explained plastic 74 mechanical properties whereas elastic mechanical properties were 75 explained by mineralization [13]. In addition, at the whole-bone level in 76 rat humerus, bone tissue material composition was a strong predictor of 77 mechanical behavior, accounting for up to $83 \%$ of the variability in bone 78 mechanics [14]. Therefore, the mechanical properties of the bone matrix 79 are important parameters to explore to enhance the understanding of 80 
mechanisms involved in bone fragility. For example, in cohort studies, bisphosphonates impacted on bone matrix formation, in addition to their well-established antiresorptive effect. They contribute, therefore, to fragility fracture prevention and highlight the necessity for assessment of the bone matrix contribution to whole bone strength $[15,16]$.

This study aimed to investigate the direct contribution of the organic and inorganic bone matrix properties to the mechanical behavior of whole human lumbar vertebrae. We hypothesized that bone matrix directly impacts mechanical behavior at the whole bone level, independently of bone mass and microarchitecture.

\section{Material and methods}

\section{Bone specimens}

Lumbar spines (L1-L5) were harvested fresh from 17 Caucasian elderly human donors ( 8 women and 9 men) aged $76 \pm 11$ years-old. Source of the donors was anatomical donation and their available medical history was limited to the cause of the death. The absence of prevalent fractures or significant bone diseases involving the lumbar spine (i.e., bone metastasis, Paget's disease, or Kellgren-Lawrence grades 3 and 4 lumbar spine osteoarthritis) was assessed using high-resolution lateral radiographs of the whole lumbar spine (Faxitron X-ray Corp., Lincolnshire, IL, USA). Then, the L2 and L3 vertebrae were separated from the lumbar spines and frozen at $-20{ }^{\circ} \mathrm{C}$ wrapped in saline-soaked gauze. Bone mass, trabecular and cortical microarchitecture and bone mechanics were measured on the L3 vertebrae [3-5]. The organic and inorganic trabecular bone matrix properties were assessed on the L2 vertebrae using Fourier transform infrared microspectroscopy (FITRM) [17].

\section{Bone mass and microarchitecture assessment}

After thawing at room temperature, bone mineral content (BMC, g) and areal lateral bone mineral density (aBMD, g/ $\mathrm{cm}^{2}$ ) of the $\mathrm{L} 3$ vertebrae was measured using dual-energy X-ray absorptiometry (DXA; Delphi W, Hologic, Waltham, MA, USA). Then, the posterior arches and surrounding soft tissues including the intervertebral disks were carefully removed. Microarchitecture was measured using a $\mu$-CT device (Skyscan 1076, Aartselaar, Belgium) on L3 vertebral bodies immerged in Ashman's solution. A nominal isotropic voxel size of $35 \mu \mathrm{m}$ was used (field of view $70 \mathrm{~mm}, 2000 \times 2000$ pixels, X-ray source: $100 \mathrm{kV}-100 \mu \mathrm{A})$. Two- to three-dimension processing, analysis and visualization were performed using Skyscan Ant ${ }^{\circledR}$ software. The following microarchitectural parameters were directly measured: trabecular bone volume per tissue volume (Tb.BV/TV, \%), trabecular thickness (Tb.Th, mm), structure model index (SMI, \#), degree of anisotropy (DA, \#), anterior cortical thickness (Ct.Th, $\mathrm{mm}$ ) and porosity (Ct.Po, \%), and anterior cortical radius of curvature (Ct.Curv, mm).

\section{Mechanical testing}

After $\mu$-CT acquisition, L3 vertebral bodies were kept moist at $+4{ }^{\circ} \mathrm{C}$ with Ashman's solution until mechanical testing. A polyester resin interface (Soloplast V11, Vosschemie, Saint-Egrève, France) with a quick-setting polymerization at low temperature (maximum exothermic peak $<+40{ }^{\circ} \mathrm{C}$ ) was applied to each endplate of the $\mathrm{L} 3$ vertebral body to achieve parallel surfaces for load application. Then, quasi-static uniaxial compressive testing was performed on the whole vertebral body submerged in $+37{ }^{\circ} \mathrm{C}$-controlled Ashman's solution using a screw-driven testing machine (Schenck RSA-250, Darmstadt, Germany) under displacement control at $0.5 \mathrm{~mm} / \mathrm{mm}$ until failure. The compressive load and displacement were measured, respectively, using a $5000 \mathrm{~N}$ load cell (F 501 TC, TME, Signes, France) and a displacement transducer mounted directly on the vertebral resin endplates (Mecanium mechanical engineering, Lyon, France). Preconditioning was performed prior to testing (10 cycles with loading at $100 \mathrm{~N}$ and unloading at $50 \mathrm{~N}$ ). The following parameters 140 were determined from the load-displacement data: failure load (N), de- 141 fined by the force at the maximum on the load-displacement curve, 142 stiffness $(\mathrm{N} / \mathrm{mm})$, defined by the linear part of load-displacement 143 curve slope between $25 \%$ and $75 \%$ of the failure load and, work to failure 144 (N.mm), defined by the area under the load-displacement curve to the 145 failure load.

FTIRM (Fourier Transform InfraRed Microspectroscopy) analysis of bone 147 matrix

L2 vertebrae were sectioned in half using an Isomet Buehler 4000149 microsaw (Buehler $\mathrm{GmbH}$, Düsseldorf, Germany). A cylindrical core 150 sample of trabecular bone was removed in the cranio-caudal direction 151 from the anterior quadrant of the right half of vertebrae using an 152 $8.25 \mathrm{~mm}$-diameter diamond tipped coring tool. The end plate of each 153 core was removed with the microsaw. Trabecular cores were fixed in 154 $70 \%$ ethanol for 2 weeks, dehydrated for $48 \mathrm{~h}$ in absolute alcohol, 155 substituted in methylcyclohexane for $48 \mathrm{~h}$ and then embedded in 156 polymethylmethacrylate (PMMA). FTIRM was performed in transmission 157 mode on $2 \mu \mathrm{m}$-thick sections with a Perkin-Elmer GXII Auto-image 158 Microscope (Norwalk, CT, USA) equipped with a wideband detector 159 (mercury-cadmium-telluride) (7800-400 $\left.\mathrm{cm}^{-1}\right)$. A Cassegrain objec- 160 tive with numerical aperture of 0.6 was used with a spatial resolution 161 of $10 \mu \mathrm{m}$ at typical mid-infrared wavelengths. Twenty measurements 162 per sample were done at $30 * 100 \mu \mathrm{m}$ of spatial resolution to cover the 163 whole surface of the vertebral trabecular core. Each spectrum was collect- 164 ed at $4 \mathrm{~cm}^{-1}$ resolution and 50 scans by spectrum in the transmission 165 mode. Contribution of air and PMMA were subtracted from the original 166 spectrum. After automatic baseline correction (Spectrum Software) and 167 curve fitting of every individual spectrum, GRAMS/AI software (Thermo 168 Galactic, Salem, NH, USA) was used to quantify the characteristics of the 169 spectra (Fig. 1). The following parameters were determined: the mineral 170 crystallinity index which is inversely proportional to the full width at 171 half-maximum of the $604 \mathrm{~cm}^{-1}$ peak (apatitic phosphate environment) 172 and corresponds to both crystal size and perfection [18], the mineraliza- 173 tion index which is the area ratio of the bands of mineral matrix over or- 174 ganic matrix (1184-910 $\left.\mathrm{cm}^{-1} / 1712-1592 \mathrm{~cm}^{-1}\right)$ [17], the mineral 175 maturity which is calculated as the area ratio of the apatitic phosphate 176 over nonapatitic phosphate $\left(1030 / 1110 \mathrm{~cm}^{-1}\right.$ area ratio) and reflects 177 the age of mineral [18], and the collagen maturity which is calculated as 178 the ratio of organic matrix bands $\left(1660 / 1690 \mathrm{~cm}^{-1}\right.$ area ratio) [18] and 179 reflects the change in secondary structure of collagen in relation to the 180 mineralization process [19] (Fig. 1).

Statistical analyses

Shapiro-Wilk tests were used to assess the normality of the distri- 183 butions. For Ct.Th, Ct.Po, Ct.Curv and work to failure, distributions 184

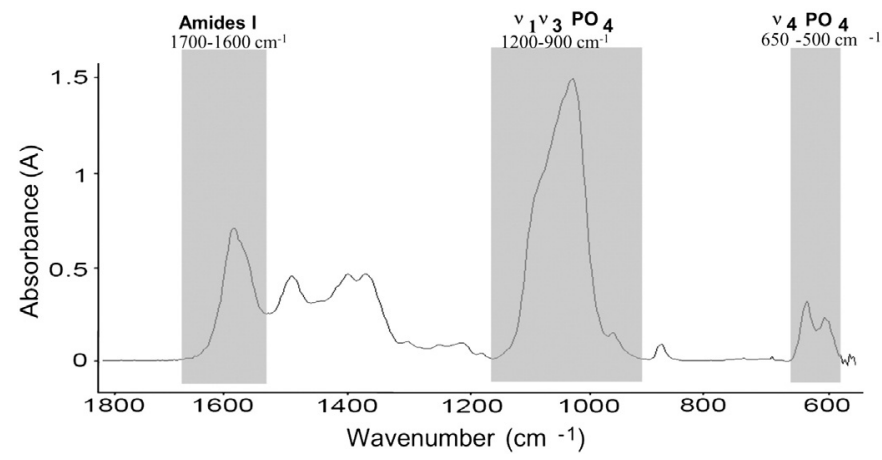

Fig. 1. Typical FTIRM spectra characteristics of a L2 core biopsy showing the peaks of amides $\left(1600-1700 \mathrm{~cm}^{-1}\right)$ of the $v_{4} \mathrm{PO}_{4}$ domain $\left(500-650 \mathrm{~cm}^{-1}\right)$ and of the $v_{1} v_{3} \mathrm{PO}_{4}$ domain $\left(900-1200 \mathrm{~cm}^{-1}\right)$. 
were normalized using logarithmic transformation. Data were presented as the mean \pm standard deviation. The following tests were used: $1 /$ paired t-tests for the comparison of two continuous variables, 2/Pearson coefficients of correlation for the analysis of the relationships between two continuous variables between gender and 3 /forward stepwise multiple regression models for the selection of variables explaining the mechanical behavior. Results were considered as significant if p-value $<0.05$. All statistical analyses were performed using SPSS ${ }^{\circledR} 16.0$ (SPSS Inc., Chicago, IL).

\section{Results}

Descriptive statistics for bone mass, microarchitecture, matrix characteristics and whole vertebra mechanics parameters are shown in Table 1. There was no influence of age on bone mass, microarchitecture, matrix and mechanics parameters. No effect of sex was found except for BMC, which was significantly higher in men than in women $(7.63 \pm 2.03 \mathrm{~g}$ vs. $5.62 \pm 1.32, \mathrm{p}=0.031$ ).

No correlation was found between the bone matrix characteristics and bone mass or microarchitecture (Table 2). The BMD and Tb.BV/TV were positively correlated with failure load, stiffness and work to failure ( $r=0.56$ to $0.69 ; p=0.002$ to 0.019 ) (Table 2 ). The SMI was negatively correlated with failure load, stiffness and work to failure $(\mathrm{r}=-0.81$, -0.58 and $-0.64 ; \mathrm{p}=<0.0001,0.014,0.005$, respectively) (Table 2 ). In addition, the parameters of thickness (i.e., Tb.Th and Ct.Th) were positively correlated with work to failure $(\mathrm{r}=0.53$ and $0.61 ; \mathrm{p}=0.027$ and 0.009 , respectively) (Table 2 ). The mineral maturity, the mineralization and the crystallinity index were not correlated with whole vertebrae mechanics (Table 2). However, the collagen maturity was positively correlated with whole vertebra failure load and stiffness $(r=0.64$; $\mathrm{p}=0.005$ and $\mathrm{r}=0.54 ; \mathrm{p}=0.025$, respectively) (Table 2).

Using forward stepwise multiple regression models to explain mechanical behavior with the following equation:

mechanical behavior(i.e.failure load, stiffness or work to failure) $=$ bone mass

(i.e.BMC, BMD or Tb.BV/TV)

+ microarchitecture

(i.e.SMI, Tb.Th, DA, Ct.Th, Ct.Po or Ct.Curv)

+ bone matrix properties

(i.e.mineralization or crystallinity index, or mineral or collagen maturity),

t1.1 Table 1

t1.2 Descriptive statistics (mean $\pm \mathrm{SD}$ ) for bone mass, microarchitecture, matrix t1.3 and mechanics.

$\mathrm{t} 1.4$

t1.5 Bone mass

t1.6 BMC $(\mathrm{g})$

t1.7 BMD $\left(\mathrm{g} / \mathrm{cm}^{2}\right)$

t1.8

Tb.BV/TV (\#)

SMI (\#)

Tb.Th (mm)

DA (\#)

Ct.Th (mm)

Ct.Po (\%)

Bone matrix
Mean \pm SD

Bone microarchitecture

Ct.Curv (mm)

\section{$6.69 \pm 1.98$}

$0.62 \pm 0.13$

Mineralization index

Crystallinity index

Mineral maturity

Collagen maturity

$16.71 \pm 4.41$

$1.77 \pm 0.20$

$0.23 \pm 0.04$

$0.43 \pm 0.03$

$0.71 \pm 0.36$

$3.15 \pm 3.44$

$33.52 \pm 17.33$

Bone mechanics

Failure load $(\mathrm{N})$

Stiffness $(\mathrm{N} / \mathrm{mm})$

Work to failure (N.mm) only the combination of BMC (1st step, $\mathrm{p}=0.001$ ), Tb.Th (2nd step, 216 $\mathrm{p}=0.007$ ) and collagen maturity (3rd step, $\mathrm{p}=0.012$ ) was signifi- 218 cant for the whole vertebra stiffness $(R=0.84, p=0.001)$.

Discussion

Beside geometry, mass and microarchitecture, bone strength is 221 influenced by the intrinsic material properties of the bone tissue, 222 i.e., the organic and inorganic bone matrix. Quality-related bone 223 markers such as enzymatic and non-enzymatic collagen cross-links 224 have been used to reflect the organic bone matrix and were intensively 225 studied in vivo as well as ex vivo [9-11]. Indeed, patients with osteopo- 226 rosis (OP), characterized by a low BMD and prevalent fractures, 227 exhibited significant reductions in enzymatic cross-links and an accu- 228 mulation of advanced glycation end-products (AGEs) in bone, without 229 alteration of collagen content, compared to age-matched healthy sub- 230 jects [9-11,20,21]. Particularly, the extent of non-enzymatic glycation 231 cross-links (AGEs) in the bone matrix has been shown to constitute a 232 major and independent predictor of bone fragility, significantly associ- 233 ated with microdamage accumulation and alterations in trabecular 234 microarchitecture resulting in a reduced fracture resistance [20,21]. In 235 addition, other studies using physicochemical degradation of cortical 236 and trabecular bone have emphasized the role of the organic bone 237 matrix to fracture mechanisms [22,23]. These suggest that fragility of 238 osteoporotic bone is related to collagen changes [22,23]. However, be- 239 side these studies, this contribution is not a straightforward analysis 240 to be explored directly at the whole-bone level, and it remains poorly 241 understood in humans. Therefore, comprehensive ex-vivo studies are 242 needed to address precisely the direct contribution of bone tissue con- 243 stituents to the whole material mechanical properties.

In the current study, we demonstrated that collagen maturity was an 245 independent predictor of the whole vertebra failure load and stiffness 246 explaining respectively $41 \%$ and $29 \%$ of their variability, independently 247 of bone mass and microarchitecture. In addition, collagen maturity in 248 combination with bone mass and microarchitecture improved predic- 249 tion of the whole vertebra stiffness, explaining $71 \%$ of its variability. 250 Interestingly, we found no significant contribution of mineralization pa- 251 rameters, evaluated by FTIRM, to whole vertebrae mechanical behavior. 252 Overall, at the microscopic level, both mineral and organic matrix contri- 253 butions are assumed to explain $100 \%$ of the mechanical properties. At 254 this scale, mineralization was demonstrated to be a major determinant 255 of elasticity, whereas organic matrix conferred bone toughness, its abil- 256 ity to deform during energy absorption without cracking [13]. At the 257 whole organ level, mineral and organic contributions become minor 258 parameters to explain the mechanical behavior, compared to bone 259 mass and microarchitecture; particularly in such a cohort of elderly 260 subjects characterized by a low BMC and BMD. Using forward stepwise 261 analyses, we demonstrated that, among the major constituents of bone, 262 collagen maturity played the third most important role in whole bone 263 strength after bone mass and microarchitecture, respectively. 264

Collagen maturity, initially described by Paschalis et al., is related 265 to the Pyridinoline (PYD)/dihydroxylysinonorleucine (DHLNL) ratio, 266 i.e. mature over immature enzymatic cross-links, and is calculated as 267 the ratio of 2 sub-bands $\left(1660 / 1690 \mathrm{~cm}^{-1}\right.$ ratio) in the amide I band 268 [19]. The amide I band in IR spectroscopy results from the stretching 269 vibration of the peptide carbonyl group $(\mathrm{C}=0)$, and is highly related to 270 the secondary structure of proteins [24,25]. In bone tissue, this band is 271 related to the organic matrix composed by $90 \%$ type I collagen and $10 \% 272$ of non-collagenous proteins. Intrinsically, several events occur simulta- 273 neously during bone maturation. After being synthesized by osteoblasts, 274 the organic matrix is rapidly mineralized. Simultaneously, organic matrix 275 dehydration occurs with bone mineralization process [26-28]. Along 276 with augmentation in the bone mineral content and improvement of 277 apatite crystal size/perfection, enzymatic and non-enzymatic cross-links 278 (PYD, deoxypyridinoline and AGEs) increase, and non-collagenous pro- 279 teins (osteopontin and osteocalcin) decrease [9,29-32]. This results in 280 
Table 2

Pearson's coefficients of correlation between bone mass, microarchitecture, matrix and mechanics. Bold characters: significant correlations.

\begin{tabular}{|c|c|c|c|c|c|c|c|c|c|c|c|c|c|c|c|}
\hline & BMD & BMC & Tb.BV/TV & SMI & Tb.Th & DA & Ct.Th & Ct.Po & Ct.Curv & $\begin{array}{l}\text { Mineralization } \\
\text { index }\end{array}$ & $\begin{array}{l}\text { Crystallinity } \\
\text { index }\end{array}$ & $\begin{array}{l}\text { Mineral } \\
\text { maturity }\end{array}$ & $\begin{array}{l}\text { Collagen } \\
\text { maturity }\end{array}$ & $\begin{array}{l}\text { Failure } \\
\text { load }\end{array}$ & Stiffness \\
\hline BMC & $0.90^{\mathrm{a}}$ & & & & & & & & & & & & & & \\
\hline Tb.BV/TV & $0.84^{\mathrm{a}}$ & $0.63^{b}$ & & & & & & & & & & & & & \\
\hline SMI & $-0.62^{b}$ & -0.45 & $-0.74^{\mathrm{b}}$ & & & & & & & & & & & & \\
\hline Tb.Th & $0.53^{\mathrm{c}}$ & $0.55^{\mathrm{c}}$ & 0.37 & -0.16 & & & & & & & & & & & \\
\hline DA & -0.26 & -0.24 & -0.30 & -0.25 & -0.23 & & & & & & & & & & \\
\hline Ct.Th & $0.48^{\mathrm{c}}$ & $0.55^{\mathrm{c}}$ & 0.30 & -0.42 & $0.76^{\mathrm{a}}$ & 0.13 & & & & & & & & & \\
\hline Ct.Po & 0.31 & 0.43 & 0.16 & -0.47 & 0.46 & 0.33 & $0.83^{a}$ & & & & & & & & \\
\hline Ct.Curv & $-0.60^{c}$ & $-0.57^{c}$ & -0.38 & 0.02 & -0.41 & 0.25 & -0.36 & 0.02 & & & & & & & \\
\hline $\begin{array}{l}\text { Mineralization } \\
\text { index }\end{array}$ & -0.15 & -0.07 & -0.04 & 0.26 & 0.15 & -0.11 & -0.17 & -0.21 & 0.21 & & & & & & \\
\hline Crystallinity index & 0.09 & 0.10 & 0.12 & 0.24 & 0.10 & -0.28 & -0.31 & -0.42 & -0.10 & $0.84^{\mathrm{a}}$ & & & & & \\
\hline Mineral maturity & 0.10 & 0.03 & 0.27 & -0.21 & -0.03 & 0.20 & -0.20 & -0.19 & 0.20 & $0.71^{\mathrm{b}}$ & $0.66^{\mathrm{b}}$ & & & & \\
\hline Collagen maturity & 0.25 & 0.06 & 0.45 & -0.47 & -0.09 & 0.36 & -0.02 & -0.03 & 0.08 & 0.04 & 0.09 & $0.64^{\mathrm{b}}$ & & & \\
\hline Failure load & $0.65^{\mathrm{b}}$ & $0.48^{\mathrm{c}}$ & $0.69^{b}$ & $-0.81^{\mathrm{a}}$ & 0.07 & 0.08 & 0.24 & 0.25 & -0.10 & -0.36 & -0.26 & 0.14 & $0.64^{\mathrm{b}}$ & & \\
\hline Stiffness & $0.56^{\mathrm{c}}$ & 0.44 & $0.57^{c}$ & $-0.58^{c}$ & -0.21 & 0.05 & -0.18 & 0.03 & 0.01 & -0.12 & 0.04 & 0.37 & $0.54^{c}$ & $0.75^{\mathrm{a}}$ & \\
\hline Work to failure & $0.58^{c}$ & 0.40 & $0.61^{\mathrm{b}}$ & $-0.64^{\mathrm{b}}$ & $0.53^{c}$ & -0.01 & $0.62^{\mathrm{b}}$ & 0.45 & -0.27 & -0.41 & -0.38 & -0.20 & 0.32 & $0.73^{a}$ & 0.18 \\
\hline
\end{tabular}

a $\mathrm{p}<0.0001$.
b $\mathrm{p}<0.001$.

c $\mathrm{p}<0.05$.

modifications of the collagen secondary structure with a tighter packing of collagen with maturation of bone [28,33,34]. Therefore, this simultaneous evolution of several parameters during maturation leads to a complex interpretation of the amide I band in bone tissue assessed by IR spectroscopy $[18,19]$. Farlay $D$ et al. demonstrated that there was no significant difference in the $1660 / 1690 \mathrm{~cm}^{-1}$ ratio in bone from lathyritic rats characterized by a massive decrease in the formation of collagen enzymatic cross-links due to the inhibition of lysyl oxidase when compared to control rats [18]. This study also demonstrated that the destruction of PYD cross-links using ultraviolet photolysis performed on bovine bone slices did not change the $1660 / 1690 \mathrm{~cm}^{-1}$ ratio when compared to control slices [18]. Such results suggested that this ratio reflected probably more changes in organic matrix maturation and hydration than changes in enzymatic cross-link content [18]. Therefore, our results demonstrated that a more mature and dehydrated organic matrix, with higher collagen packing, was associated with improved bone mechanical behavior of whole vertebrae (i.e., failure load and stiffness). Similarly, in biomaterials science, nanofibers in nanocomposite materials are glued to each other in the absence of water, due to molecular level interactions resulting in a strong and rigid material [35]. However, when water is added, water molecules unglue the nanofibers and the material becomes softer [35]. Indeed, using nanoindentation ex vivo, Bembey AK et al. observed that a hydration increase was associated with decrease in bone tissue stiffness, while a hydration decrease resulted in increased stiffness [36]. In addition, Nyman JS et al. showed that removal of water from the bone matrix using drying conditions impaired significantly mechanical properties of human cortical bone [37]. Therefore, the collagen and its level of maturity and hydration were demonstrated to be important determinants of bone strength independently of mineralization. Our data support the conclusion that disorganization of the organic matrix has a major role in the fracture risk. This observation can be illustrated in the pathophysiology of osteogenesis imperfecta (OI). That is, despite the absence of bone microarchitectural abnormalities, and even with an increased matrix mineralization, the OI bones are highly brittle due to a mutation in the collagen-type 1 triple-helix molecule, resulting in low bone matrix stiffness due to disorganization of the organic matrix $[38,39]$.

This study presented with five main limitations. The first limitation is related to our limited sample size that might underpower this study, particularly regarding the absence of correlation with mineralization parameters. Second, the average age of our subjects was 76 years, so the results might not be representative of the general population, but rather of an elderly population. However, the elderly population is the most susceptible to fragility fracture. Third, whole vertebra mechanics were assessed using quasi-static uniaxial compressive loading. Other loading conditions that are relevant for vertebral fracture such as cyclic fatigue, 325 bending or shearing may have different associations with bone mass, 326 microarchitecture and matrix properties. Fourth, bone matrix properties 327 and mechanical behavior were measured on different though adjacent 328 vertebrae since both of these analyses induced damage to the vertebra. 329 Finally, this study was focused on FTIRM analysis of the bone matrix 330 and did not evaluate other aspects of the matrix such as enzymatic 331 and non-enzymatic collagen cross-links, collagen content or degree of 332 mineralization.

In conclusion, collagen maturity was an independent predictor of 334 whole vertebra failure load and stiffness, and explained more than 335 two-third of the stiffness variability in combination with bone mass 336 and microarchitecture. No relationship between mineralization pa- 337 rameters and whole vertebra mechanics was found in this study fo- 338 cused on an elderly patient cohort.

\section{Acknowledgments}

No external source of funding is disclosed. The authors thank 341 Dr. Mark Forwood, PhD, for his assistance in manuscript preparation 342 and review.

Disclosure

All authors state that they have no conflict of interest that might 347 bias this study.

\section{References}

[1] Bouxsein ML. Determinants of skeletal fragility. Best Pract Res Clin Rheumatol 350 2005;19:897-911.

[2] Cole JH, van der Meulen MCH. Whole bone mechanics and bone quality. Clin 352 Orthop Relat Res 2011;469:2139-49.

[3] Roux JP, Wegrzyn J, Arlot ME, Guyen O, Delmas PD, Chapurlat R, et al. Contribution 354 of trabecular and cortical components to biomechanical behavior of human vertebrae: 355 an ex vivo study. J Bone Miner Res 2010;25:356-61.

[4] Wegrzyn J, Roux JP, Arlot ME, Boutroy S, Vilayphiou N, Guyen O, et al. Role of 357 trabecular microarchitecture and its heterogeneity parameters in the mechanical 358 behavior of ex vivo human L3 vertebrae. J Bone Miner Res 2010;25:2324-31. 359

[5] Wegrzyn J, Roux JP, Arlot ME, Boutroy S, Vilayphiou N, Guyen O, et al. Determi- 360 nants of the mechanical behavior of human lumbar vertebrae after simulated 361 mild fracture. J Bone Miner Res 2011;26:739-46.

[6] Boutroy S, Bouxsein ML, Munoz F, Delmas PD. In vivo assessment of trabecular 363 bone microarchitecture by high-resolution peripheral quantitative computed 364 tomography. J Clin Endocrinol Metab 2005;90:6508-15.

[7] Sornay-Rendu E, Boutroy S, Munoz F, Delmas PD. Alterations of cortical and trabecu- 366 lar architecture are associated with fractures in postmenopausal women, partially 367 independent of decreased BMD measured by DXA: the OFELY study. J Bone Miner 368 Res 2007;22:425-33. 
[8] Burr DB. The contribution of the organic matrix to bone's material properties. Bone 2002;31:8-11.

[9] Viguet-Carrin S, Garnero P, Delmas PD. The role of collagen in bone strength. Osteoporos Int 2006;17:319-36.

[10] Saito M, Marumo K. Collagen cross-links as a determinant of bone quality: a possible explanation for bone fragility in aging, osteoporosis, and diabetes mellitus. Osteoporos Int 2010;21:195-214.

[11] Viguet-Carrin S, Roux JP, Arlot ME, Merabet Z, Leeming DJ, Byrjalsen I, et al. Contribution of the advanced glycation end product pentosidine and of maturation of type I collagen to compressive biomechanical properties of human lumbar vertebrae. Bone 2006;39:1073-9.

[12] Boivin G, Bala Y, Doublier A, Farlay D, Ste-Marie LG, Meunier PJ, et al. The role of mineralization and organic matrix in the microhardness of bone tissue from controls and osteoporotic patients. Bone 2008;43:532-8.

[13] Bala Y, Depalle B, Douillard T, Meille S, Clément P, Follet H, et al. Respective roles of organic and mineral components of human cortical bone matrix in micromechanical behavior: an instrumented indentation study. J Mech Behav Biomed Mater 2011;4: 1473-82.

[14] Donnelly E, Chen DX, Boskey AL, Baker SP, van der Meulen MCH. Contribution of mineral to bone structural behavior and tissue mechanical properties. Calcif Tissue Int 2010;87:450-60.

[15] Bala Y, Depalle B, Farlay D, Douillard T, Meille S, Follet $H$, et al. Bone micromechanical properties are compromised during long-term alendronate therapy independently of mineralization. J Bone Miner Res 2012;27:825-34.

[16] Hofstetter B, Gamsjaeger S, Philipps RJ, Recker RR, Ebetino FH, Klaushofer K, et al. Effects of alendronate and risedronate on bone material properties in actively forming trabecular bone surfaces. J Bone Miner Res 2012;27:995-1003.

[17] Paschalis EP, DiCarlo E, Betts F, Sherman P, Mendelsohn R, Boskey AL. FTIR microspectroscopic analysis of human osteonal bone. Calcif Tissue Int 1996;59: $480-7$.

18] Farlay D, Duclos ME, Gineyts E, Bertholon C, Viguet-Carrin S, Nallala J, et al. The ratio $1660 / 1690 \mathrm{~cm}^{-1}$ measured by infrared microspectroscopy is not specific of enzymatic collagen cross-links in bone tissue. PLoS One 2011;6:e28736.

[19] Paschalis EP, Verdelis K, Doty S, Boskey AL, Mendelsohn R, Yamauchi M. Spectroscopic characterization of collagen cross-links in bone. J Bone Miner Res 2001;16:1821-8.

[20] Tang SY, Vashishth D. Non-enzymatic glycation alters microdamage formation in human cancellous bone. Bone 2010;46:148-54.

21] Karim L, Vashishth D. Heterogeneous glycation of cancellous bone and its association with bone quality and fragility. PLoS One 2012;7:e35047.

[22] Fantner GE, Birkedal H, Kindt JH, Hassenkam T, Weaver JC, Cutroni JA, et al. Influence of the degradation of the organic matrix on the microscopic fracture behavior of trabecular bone. Bone 2004;35:1013-22.
[23] Zioupos P. Currey JD, Hamer AJ. The role of collagen in the declining 412 mechanical properties of aging human cortical bone. J Biomed Mater Res 1999;45: 413 $108-16$.

[24] Krimm S, Bandekar J. Vibrational spectroscopy and conformation of peptides, 415 polypeptides, and proteins. Adv Protein Chem 1986;38:181-364. 416

[25] Byler DM, Susi H. Examination of the secondary structure of proteins by 417 deconvolved FTIR spectra. Biopolymers 1986;25:469-87. 418

[26] Wehrli FW, Fernandez-Seara MA. Nuclear magnetic resonance studies of bone 419 water. Ann Biomed Eng 2005;33:79-86.

[27] Elliott SR, Robinson RA. The water content of bone. J Bone Joint Surg Am 1957;39: 421 $167-88$.

[28] Lees S. Considerations regarding the structure of the mammalian mineralized 423 osteoid from viewpoint of the generalized packing model. Connect Tissue Res 424 1987;16:281-303.

[29] Farlay D, Panczer G, Rey C, Delmas PD, Boivin G. Mineral maturity and crystallinity 426 index are distinct characteristics of bone mineral. J Bone Miner Metab 2010;28: 427 433-45.

[30] Sroga GE, Karim L, Colon W, Vashishth D. Biochemical characterization of 429 major bone-matrix proteins using nanoscale-size bone samples and proteomics 430 methodology. Mol Cell Proteomics 2011;10 [M110.006718].

[31] Boivin G, Farlay D, Bala Y, Doublier A, Meunier PJ, Delmas PD. Influence of remod- 432 eling on the mineralization of bone tissue. Osteoporos Int 2009:20:1023-6. 433

[32] Boskey A. Bone mineral crystal size. Osteoporos Int 2003;14:16-21. 434

[33] Mogilner IG, Ruderman G, Grigera JR. Collagen stability, hydration and native 435 state. J Mol Graph Model 2002;21:209-13.

[34] Zhu P, Xu J, Sahar N, Morris MD, Kohn DH, Ramamoorthy A. Time-resolved 437 dehydration-induced structural changes in an intact bovine cortical bone revealed 438 by solid-state NMR spectroscopy. J Am Chem Soc 2009;131:17064-5.

[35] Capadona JR, Shanmuganathan K, Tyler DJ, Rowan SJ Weder C. Stimuli-responsive 440 polymer nanocomposites inspired by the sea cucumber dermis. Science 2008;319: 441 $1370-4$.

36] Bembey AK, Oyen ML, Bushby AJ, Boyde A. Viscoelastic properties of bone as a 443 function of hydration state determined by nanoindentation. Philos Mag 2006;86: 444 5691-703.

[37] Nyman JS, Roy A, Shen X, Acuna RL, Tyler JH, Wang X. The influence of water 446 removal on the strength and toughness of cortical bone. J Biomech 2006;39: 447 931-8.

[38] Roschger P, Paschalis EP, Fratzl P, Klaushofer K. Bone mineralization density 449 distribution in health and disease. Bone 2008:42:456-66. 450

[39] Vanleene M, Porter A, Guillot PV, Boyde A, Oyen M, Shefelbine S. Ultra-structural 451 defects cause low bone matrix stiffness despite high mineralization in osteogenesis 452 imperfecta mice. Bone 2012;50:1317-23. 